\title{
Wolffian Adnexal Tumor
}

National Cancer Institute

\section{Source}

National Cancer Institute. Wolffian Adnexal Tumor. NCI Thesaurus. Code C40141.

A benign or malignant epithelial neoplasm of probable Wolffian origin. It predominantly arises from the broad ligament and presents as a unilateral adnexal mass. 